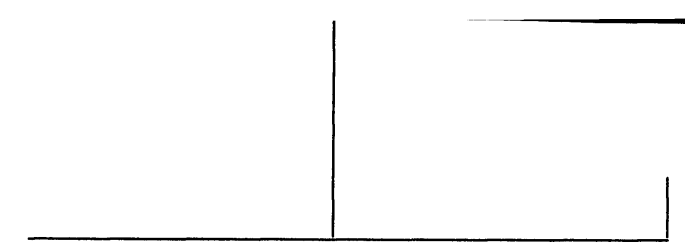

Rev. Latinoam. Psicopat. Fund., VIII, 4, 721-737

\title{
Um estudo, uma denúncia e uma proposta: a psicanálise na interlocução com outros saberes em saúde mental, como avanço do conhecimento sobre o sofrimento psíquico
}

\author{
Sonia Alberti \\ Ana Paula Marques Lettieri Fulco
}

Introdução

É possível supor que a história do conhecimento teve uma interrupção de mais ou menos três séculos a partir das Cruzadas, quando o mundo teve o saber adquirido trancafiado nas torres dos monastérios. No século XVI, o início da falência do domínio da Igreja, que então detinha o saber sobre as coisas, possibilitou o surgimento de outras teorias explicativas. A derrubada de grandes verdades levou a descobertas, invenções, transformações políticas e religiosas (GarciaRoza, 1988). Se desde o século XV já se resistia às explicações religiosas sobre as coisas do mundo, o século XVI conheceu toda uma nova Weltanschauung - a revolução se intensificou contra o saber absoluto da Igreja Católica; apareceram as teorias renascentistas sobre as coisas do Universo e sobre o homem, e se deu o início da

* Este texto recebeu o Prêmio Internacional Pierre Fédida de Ensaios Inéditos de Psicopatologia Fundamental - 2004, concedido pela Associação Universitária de Pesquisa em Psicopatologia Fundamental. 


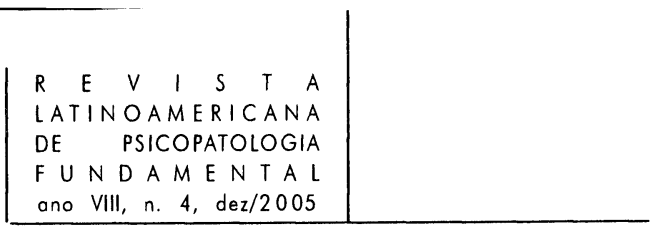

investigação científica numa proposta de dissociar as influências teológica e escolástica, da investigação da realidade.

Diante da incerteza quanto à realidade do mundo objetivo - em função do corte com o dogmatismo religioso -, Descartes afirma a certeza do cogito Penso, logo existo. O homem existe porque é possível inscrevê-lo no simbólico, no pensamento que lhe dá uma morada no cogito. Descartes distinguiu um mundo em que as coisas existem através de sua representação conceitual, deixando de fora outro mundo onde as coisas não são conceituadas. Era então a criação de um novo discurso: o da ciência.

Nele, a realidade era composta de duas áreas distintas e separadas, o domínio físico, da matéria, e o reino imaterial da mente (cf. Henneman, 1966). Para Abbgnano (1971), a concepção do dualismo alma e corpo, de Descartes, estabeleceu certa independência com relação àquela postulada anteriormente pela escolástica, que entendia o corpo como mero instrumento da alma. Apesar da nova proposta, as considerações de Descartes sobre o dualismo não esclareceram a natureza da relação entre o corpo e a alma. As perguntas de como e por que tais substâncias se combinam para formar o homem mantêm-se desde então, e norteiam os debates entre muitas teorias. Nem sempre foi assim, haja vista o exemplo melhor da prática da medicina medieval, com Avicena (cf. Gordon, 1986). É no contexto cartesiano que também se deu o nascimento da clínica, estudado por Foucault (1980).

A partir do século XIX - depois do Iluminismo, portanto, e do boom taxionômico iniciado nas ciências naturais -, a própria medicina, primeiro por meio da anatomia patológica, depois com a fisiologia, procurou reduzir o homem a um objeto cientificamente investigável (ibid.). Para isso surgiu a preocupação com novas causalidades, fazendo da medicina uma prática causal: “... todo fenômeno tem uma causa", o que condiz com o princípio da causalidade (Lalande, 1926, p. 147). Para aí evitar o erro, seria necessário ater-se incessantemente ao contato com a experiência e renunciar a todo e qualquer a priori. Crendo poder fazê-lo, a medicina incluiu nela o positivismo. Este, avesso à psicologia, por definição, considerava-a fora da ciência, e qualquer explicação sobre o psiquismo - que não recorresse ao orgânico e ao experimentável - passou a ser considerada como não científica. O sujeito, ele mesmo, ficou órfão desta cientificidade.

Durante o século XIX houve um tempo em que tanto a teologia quanto a filosofia, e ainda a medicina, se ocuparam do corpo e da alma. Mas a história das psicologias nos mostra que a tentativa de entender e explicar os fenômenos psíquicos tendeu, neste contexto, à opção de se traçar uma correlação direta, biunívoca, entre os fenômenos psíquicos e suas causas - geralmente químicas, fisiológicas ou anatômicas. Este é o legado da revolução científica de Descartes, 


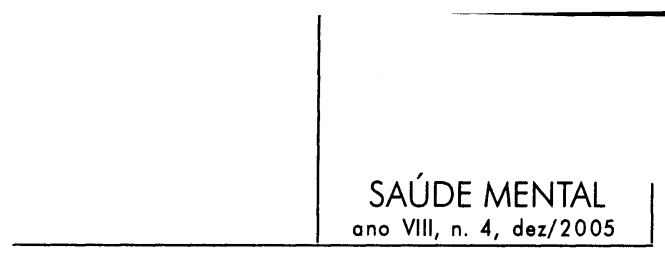

com o qual temos que nos haver. O primeiro a melhor denunciá-lo foi Hugglings Jackson (1878) e depois, com ele, veio Freud, ambos a partir do tema das afasias. Com efeito, em 1891, em seu texto "A interpretação das afasias", Freud observava, conforme retoma o eminente colega inglês, Mark Solms, a seguinte pérola:

Eu bem que sei que os autores a cujos pontos de vista me oponho não podem ser culpabilizados por erros grosseiros em seus estudos científicos. Obviamente eles querem dizer que as modificações fisiológicas da fibra nervosa através dos estímulos sensoriais produzem outra modificação nas células centrais que então se tornam correlatos fisiológicos do "conceito" ou da "idéia". Na medida em que eles conhecem melhor as idéias do que as modificações nervosas, que ainda estão indefinidas e desconhecidas, eles usam a frase elíptica: uma idéia está localizada numa célula nervosa. Mas essa substituição leva, de imediato, a uma confusão de dois processos, que não precisam ter nada em comum entre si. Para a psicologia, a simples idéia é algo elementar, e pode ser claramente diferenciada da conexão com outras idéias. Eis porque se é tentado a assumir que seu correlato fisiológico, isto é, a modificação das células nervosas originada da estimulação das fibras nervosas, também pode ser algo simples e localizável. Mas tal inferência é, evidentemente, sem garantias; as qualidades dessa modificação devem ser estabelecidas por elas mesmas e independentemente de sua concomitância psicológica. (Freud, apud Solms, 1998, p. 3, tradução e grifos nosso)

A partir disso, qual a postura que hoje se observa nos textos dos neurocientistas?

Alguns estudos atuais, não podendo esquivar-se da metodologia de trabalho que impera na medicina desde o século XIX, insistem em procurar nas disfunções químicas e anatômicas, através de exames complexos (de imagens; de extremo avanço tecnológico, e medições bioquímicas as mais complexas), a causalidade para os fenômenos que alguns pacientes apresentam. Acreditam que para trabalhar com o que é da ordem do psíquico, precisam de intervenções no corpo orgânico, o que hoje identificamos com o organicismo. Nele, os organismos vivos não são "nada mais do que máquinas" (Campos, 2001, p. 8), explicáveis pelas leis da mecânica, da física e da química, o que traz prejuízos incalculáveis para toda e qualquer positivação do sujeito, contra o que a psicanálise é, provavelmente, o mais sólido instrumento - é interessante notar que, na amostra de Figueiredo (1997, p. 94-6), são os psicanalistas de alguma forma referidos a Lacan os que mais sustentam esse ponto de vista no serviço público. Cada campo do conhecimento traça explicações de acordo com o seu referencial teórico, mas o que se verifica na multidisciplinaridade numa equipe de saúde, em que coexistem a psicanálise, a neurologia, a psiquiatria e as neurociências é a necessidade de sempre novamente lembrar que a particularidade da clínica é a de fazer valer o sujeito. E o discurso do psicanalista é o único a se dirigir propriamente para o 


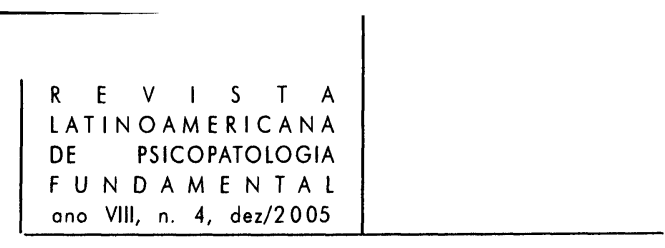

sujeito (Lacan, 1968-9). Pensar aqui a relação existente entre alma e cérebro visa a um alerta: que limites e que competências há entre a medicina e a psicanálise no atendimento da saúde mental?

\section{A psicopatologia e as ciências humanas}

Com o positivismo, as ciências do homem foram colocadas no topo do edifício das ciências experimentais e, se por um lado com isso foram reconhecidas, por outro, em realidade, subordinadas. "Essa noção provém de uma visão errônea da história das ciências, baseada no prestígio de um desenvolvimento especializado dos experimentos" (Lacan, 1953, p. 285). As razões que determinam tal engano certamente têm suas origens no próprio movimento ideológico, e mesmo econômico, da revolução burguesa, nos quais poderíamos observar dois grandes movimentos:

Em primeiro lugar, o da cientifização das disciplinas - que, até então, se ocupavam da alma -, com a finalidade de incluí-las no rol das ciências, e da redução metodológica de suas práticas que, cada vez mais, exilam os discursos a insistirem na subjetividade. Assim, por exemplo, o que se verifica hoje nesse movimento é que a própria psicanálise - certamente um saber com consistência teórica - é reduzida a uma folk psychology, ou seja, a uma psicologia popular, acientífica. Chega-se a dizer que tal psicologia é causa da maior doença que assolou a sociedade americana (Torrey apud Bilder, 1998, p. X). Qualquer construção teórica que não siga as bases experimentais, é descartada como acientífica. Para tais autores, além disso, o conceito de ciência não deixa de ter sido afinado com o positivismo.

E em segundo lugar, o da insistência na importância da subjetividade. Com Lacan, esse segundo movimento se verifica nos avanços particulares de algumas disciplinas, no século XIX, especialmente a lingüística, a etnografia estrutural e a teoria geral dos símbolos. Lacan observa que tal movimento se baseia na especificidade da referência simbólica para a pesquisa da subjetividade. Em função disso, o que associa esse movimento com a ciência não é a experimentalidade, mas as consequiências dos avanços da matemática e da história, ambos determinando uma nova forma de ver o mundo.

Com efeito, somente a partir do Iluminismo, e sobretudo no século XIX, foram encontradas as respostas para inúmeros problemas matemáticos até então impossíveis de resolver e que permitiram, para dar somente um pequeno exemplo, estudar as relações entre conjuntos - coisa até então impensável... Isso implicará as leis da intersubjetividade nas ciências conjecturais, ou seja, no campo da lógica 
e da matemática moderna. Quanto à história, é também somente no século XIX que o homem pode fazer greve geral! - isso não é pouca coisa num mundo até então submetido à ordem do Um (só para retornar à referência matemática).

Ao mesmo tempo em que os discursos tentavam se inscrever a partir de uma relação com a ciência, como visto, impunha-se cada vez mais o organicismo, conforme o primeiro modelo, da cientificização das disciplinas. É no segundo movimento, ao lado da lingüística, da etnologia, da antropologia, da história e da lógica-matemática que a psicanálise se inscreve; dentre as psicologias, não somente a psicanálise, mas sem dúvida ela, do modo como queria Freud (1895), a acolher em seu campo a psicopatologia. Nela, o homem é efeito lógico do entrecruzamento dos campos da linguagem e do gozo, e a clínica permite estabelecer este homem, “... portador de um excesso, de uma dor, de um sofrimento psíquico a respeito do qual fala sem parar, ainda que não o diga constantemente" (Berlinck, 1999, p. 27), como capaz de elaborar, na transferência, o que desse entrecruzamento o adoece.

Mas, por mais absurdo que isso possa parecer, ao longo do século $\mathrm{XX}$ a própria psicanálise conheceu destinos que, como temia Freud (1927, p. 286), quiseram esvaziar seu fundamento, e a tentativa de inscrever a psicanálise no discurso médico sem dúvida foi um dos responsáveis. Diante do embaraço que a clínica psicanalítica presentifica no quotidiano de sua prática, não poucas vezes acaba-se lançando mão de explicações que já não apostam na capacidade de o próprio sujeito elaborar seu sofrimento. Haja vista a importante gama de psicanalistas que hoje buscam as neurociências para darem conta de fenômenos. Ainda nos encontramos numa grande Babel. Crê-se já estar no futuro apontado por Freud na frase: "O futuro pode ensinar-nos a exercer influência direta, através de substâncias químicas específicas, nas quantidades de energia e na sua distribuição no aparelho psíquico" (Freud, 1938, p. 210), e se crê que hoje já saibamos exatamente quais as afecções psíquicas que efetivamente se beneficiariam das influências "eletroquímicas".

Em suas "Notas para uma teoria geral da psicopatologia fundamental", Manoel Berlinck propõe que Freud teria construído uma "psicopatologia geral da humanidade" que leva em conta, por um lado, a catástrofe ${ }^{1}$ e, por outro, a filogênese (Berlinck, 1999, p. 34). Propõe também que "A teoria psicopatológica geral da humanidade é somática, eminentemente biológica e naturalista". Paradoxalmente, em seu texto original sobre o tema, observava que a psicanálise é "a casa mais confortável existente na contemporaneidade para a Psicopatologia

1. Termo que se associa com o encontro com o real conceituado por Jacques Lacan - um dos três registros da estruturação do sujeito, o real serve aqui para indicar os maus encontros que o destino reserva ao homem. 


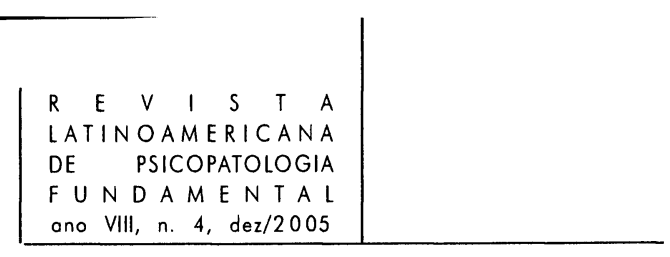

Fundamental" (Berlinck, 1998, p. 24). Isso distingue a psicanálise da psicopatologia fundamental que "não se confunde com ela" (ibid.), ao mesmo tempo em que levanta a importante questão sobre a relação entre o somático, o biológico, o naturalista e a psicanálise.

Tal questão, muito além de meramente teórica é, na realidade, impactante para cada psicanalista que trabalhe tanto no consultório quanto em algum serviço de saúde mental no Brasil, hoje. Não raro, se verifica a dicotomia propriamente dita entre psíquico e somático, a tal ponto que há verdadeiras divisões nos próprios serviços e encaminhamentos em função dessa dicotomia. Assim, é possível encontrar setores, nos serviços de saúde mental, que trabalham exclusivamente com a idéia de que todo fenômeno mental tem origem somática, e outros que não levam em conta de forma alguma a determinação somática dos processos psíquicos. Se com Descartes houve uma divisão entre corpo e pensamento no âmbito da teoria, o que se pode encontrar hoje é tal divisão na prática clínica: ou res cogitans, ou res extensa.

Quando indagamos as diretrizes públicas para a saúde mental, ${ }^{2}$ lemos que esta deve abrir lugar para as neurociências que "constituem um ramo da ciência que se dedica à anatomia, fisiologia, bioquímica e biologia molecular do sistema nervoso" (p. 29), mas também ao "funcionamento do cérebro humano vivo enquanto sente e pensa" usando uma "combinação com a neurociência cognitiva" (ibid.). Tal proposta pode visar a interdisciplinaridade na fundamentação de nossas práticas, porém, por outro lado, surge de maneira surpreendente para o psicanalista, que não encontra, nestas mesmas diretrizes, referência esclarecedora sobre o lugar da psicanálise. Ainda com Berlinck (1999) articulamos a questão: $\mathrm{Se}$ as neurociências podem ajudar a avançar as pesquisas no campo da psicopatologia, isso não impede que nos perguntemos sobre o lugar dos investimentos libidinais e da pulsão, nesse corpo em que se manifesta a psicopatologia humana (p. 40). Na realidade, tal questão se faz tanto mais necessária e urgente, quanto mais nos voltamos para uma medicina que supõe à ciência a resposta para todos os impasses clínicos. Primeiro porque é preciso sempre novamente sublinhar que a ciência não tem toda resposta para o homem e que seu discurso, pelo menos originalmente, sabe a falácia de uma crença nesse sentido e, segundo, porque são as exigências do discurso que remete à ciência aquelas que hoje também podem servir à psicanálise para melhor dizer a que veio. Ou seja, as exigências do discurso da ciência podem ser aproveitadas pelo psicanalista para afinar seu próprio instrumento e melhor transmitir o que está em jogo na articulação com os outros saberes. Mas isso, necessariamente, tem que ser verificado na clínica.

2. "Relatório sobre a saúde no mundo 2001: Saúde mental, nova concepção, nova esperança" publicado pela OMS e traduzido pelo Ministério da Saúde em 2002. 
Daí a gravidade do momento. Algumas vezes até parece que é no campo da clínica que mais se faz sentir a influência da crença de que a ciência teria resposta para tudo. Como dizia Gilda Paoliello, ${ }^{3}$ às vezes os laboratórios até levam mais em conta a existência do "sujeito", em seus estudos experimentais, do que os médicos que medicam nos consultórios e serviços de saúde mental:

A medicina, regida pela ética da ciência, tem, como ponto de partida para o tratamento, os sintomas e, como objetivo final, a abolição dos mesmos - o restitutio ad integrum, possibilitando a avaliação estatística dos resultados, seguindo condutas terapêuticas padronizadas, de acordo com os famosos guidelines que estão na ordem do dia e que vêm sendo incorporados pela Psiquiatria com a maior avidez. Aliás, uma tendência da psiquiatria atual vem fazendo um movimento bastante inusitado: enquanto os laboratórios farmacêuticos vêm cada vez mais valorizando as pesquisas naturalísticas, considerando a atuação dos medicamentos na clínica, ou seja, com o paciente real como sujeito da pesquisa (se contrapondo ao paciente ideal), não é raro encontrarmos na clínica atual o caminho inverso, levando o modelo científico para os consultórios, com o paciente sendo examinado através de escalas e encaixando-o em protocolos de diagnóstico e conduta, fazendo corresponder ao duplo-cego da pesquisa um duplo-surdo na clínica! ${ }^{4}$ (grifos nosso)

Um sujeito atualmente em tratamento psicanalítico o confirma: encaminhada por amigos, Lucia disse estar em tratamento há alguns meses com um neurologista que a medica em razão de um sintoma neurológico - em nosso diagnóstico, fobia de altura e lugares fechados. No momento em que apresenta uma nítida melhora do sintoma - conosco elabora seus conflitos diante de uma possível maternidade que a prenderia -, o neurologista aumenta a dosagem da medicação numa visível manobra de tentar se assenhorear dos resultados.

Para questionarmos essas inusitadas manobras de discurso em que, como diz Gilda Paoliello, até mesmo o modelo utilizado pelos laboratórios parece valorar mais os sujeitos enquanto tais do que a própria prática clínica, retomemos nossa história, teoria e doutrina. Examinemos o lugar da psicanálise na saúde mental, a fim de verificar de que maneira a psicopatologia geral da humanidade pode encontrar abrigo também na clínica cotidiana e nos serviços de saúde mental, se é verdade que ela encontra na psicanálise "a sua casa mais confortável". ${ }^{5}$

3. No Colóquio Brasileiro de Psiquiatria, em outubro de 2003, na Universidade de São Paulo.

4. Trecho da fala de Gilda Paoliello, no mesmo Colóquio de 2003.

5. Berlinck, M. T. Psicopatologia fundamental. As agruras de nossa clínica cotidiana já são tantas que seria bastante interessante podermos contar, pelo menos, com algum conforto. Já que isto não é exatamente o que prima nas instituições em que trabalhamos, que ao menos o encontremos no lastro que nos norteia! 


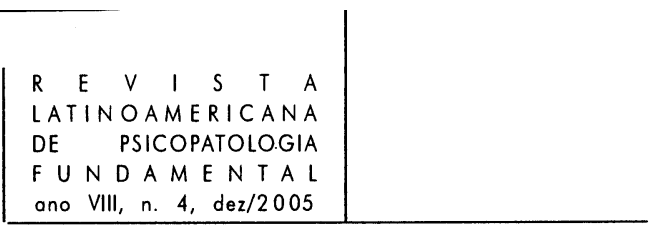

A clínica da res extensa

Ingênuo seria acreditar que três séculos de elaboração da revolução científica que aqui identificamos com Descartes, não fossem ter seus efeitos na prática cotidiana. Aqui, a prática em questão é a da clínica, de cuja história tentamos às vezes nos esquecer apesar de tantos estudos críticos nesses últimos cinqüenta anos (Foucault, 1980; Clavreul, 1978; Lacan, 1966, para citar somente os autores que, quanto a isso, nos norteiam mais particularmente).

Nosso ponto de partida é que tal determinação histórica vem na contramão, justamente, de uma interdisciplinaridade que articularia os saberes da res extensa com os da res cogitans. A ausência de tal articulação cria um hiato. Enquanto se aguarda novas diretrizes, sem dúvida há angústia entre os próprios trabalhadores da saúde mental, pois o atual momento "... em que a pragmática da prescrição de novas moléculas tende a fazer desaparecer a psicopatologia" (Fédida, 1999, p. 12) promove descrições e mais descrições nosológicas para adaptar o fenômeno que o paciente apresenta, enquadrá-lo no arcabouço teórico já conhecido de cada profissional, para justificar uma resposta em nível de um medicamento. Mesmo que as classificações sejam necessárias, ao mesmo tempo podem funcionar como falsas obturações. O sujeito aparece na clínica médica, mas, de acordo com a "Apresentação" do DSM-III, esta deve se tornar ahistórica, ateórica e adoutrinária $^{6}$ - o que ali se lê com todas as letras -, como se isso fosse não só possível como até desejável... Não há ciência sem ideologia, já dizia, em 1970, Thomas Kuhn.

A fim de melhor enquadrar as afecções mentais e orgânicas, os nomes das doenças crescem como suas novas formas. Tal situação é definida por Laurent (2000) como a de um novo nominalismo: efeito do evolucionismo na psiquiatria que leva somente à feitura de novos medicamentos, mas não tem como consequiência o tratamento psíquico. Inúmeras são as nomeações nosológicas que pretendem corresponder aos diferentes fenômenos apresentados pelos sujeitos aos médicos, e que invadem a clínica até mesmo neurológica, em que, por exemplo, se prescrevem imipraminas utilizadas para a hiperatividade e para o distúrbio do déficit de atenção, e o inibidor de recaptação de serotonina para o transtorno obsessivo compulsivo. A massa de produção de fármacos e sua utilização pelos profissionais médicos - neurologistas e psiquiatras - relega os problemas de saúde

6. Para corroborá-lo aqui, traduzimos duas frases da internet: Com o DSM-III "o ponto de vista dinâmico foi abandonado e o modelo médico se tornou o primário, introduzindo a clara distinção entre o normal e o anormal. O DSM se tornou 'ateórico' já que não privilegia nenhuma etiologia”. In: http://en.wikipedia.org/wiki/Diagnostic_and_Statistical_Manual_of_Mental_ Disorders. 
mental às trocas químicas, às deformidades anatômicas ou aos danos neurofisiológicos.

Desde 1890, em "Tratamento psíquico ou anímico", Freud já estava a par de que a química produzia mudanças comportamentais. Essa verdade é irrefutável, mas valer-se dela para explicar toda e qualquer causa para os fenômenos que assolam os sujeitos com transtornos psíquicos significa não só excluir a existência do que, em psicanálise, nomeamos de efeito sujeito, para além do corpo orgânico, como também excluir a possibilidade inversa: de que transtornos psíquicos podem assolar o organismo. Há uma Outra ${ }^{7}$ cena para ser investigada, êxtima ao corpo de órgãos.

Os avanços da medicina até hoje têm sido fundamentais. Mas o que ocasiona essa devoção ao científico experimental, para além do experimento? Que pregnância há para a humanidade nas demonstrações feitas pelos exames de ressonância magnética ou de tomografia computadorizada que excluem da cena da investigação o que há de particular em cada caso - o sujeito. À medicina foi necessária uma reviravolta para ganhar estatuto de ciência. Marco que produziu efeitos na condução atual dos tratamentos. Os estudos através das estatísticas e dos grupos de controle retratam este quadro. A investigação médico-científica visa, através de um certo número de casos, possibilitar inferir uma ação maior, em larga escala. Afinal, a falta de cuidado poria em risco a humanidade. Esse é o trabalho das campanhas epidemiológicas. Mas é assim que também surgem as idiossincrasias. São elas que justificam a psicopatologia, não levada em conta na epidemiologia. Trata-se, na realidade, de dois campos diferentes, um visando a higiene, o outro, a clínica. E não se dar conta disso, certamente traz problemas.

\section{O caso Márcia, ${ }^{8}$ uma denúncia}

Márcia tem cinco anos quando é atendida num serviço de saúde mental. Vinha encaminhada da neurologia. Sua história, no hospital, começou quando chegou com diarréia crônica ao setor de pediatria aos dois anos e meio de idade. Os médicos que a atenderam nessa época também suspeitaram de distúrbio de comportamento e, em função disso, a encaminharam para a neurologia, o que já denota uma particularidade na interpretação da fenomenologia.

7. Termo criado por Fechner e retomado por Freud, para designar o campo do sujeito inconsciente.

8. De Daniela Prata Veloso "Questionando a medicação". Trabalho apresentado no I Congresso de Psicologia: Ciência e Profissão. Universidade de São Paulo, 2002. 


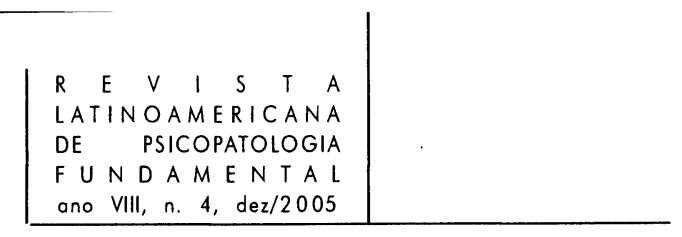

A neurologista identifica: dificuldade para dormir, comportamento irascível, impulsividade e agressividade desde os dois anos de idade e diagnostica "distúrbio de comportamento secundário - ADHA" (sic) pressupondo, portanto, uma disfunção neurológica como primária. Receitou Dogmatil - um neuroléptico.

Meio ano depois não teria havido qualquer alteração do quadro e a médica preencheu o prontuário com a seguinte observação: "TDAH, Transtorno de Déficit de Atenção e Hiperatividade" (que talvez tenha alguma analogia com o tal ADHA anterior?), e "problemática social secundária ao comportamento da menina". $\mathrm{O}$ que podemos entender daí? Que o contexto social no qual a criança está inserida está sendo influenciado por seu comportamento? Ou que este mesmo contexto social também é um fator secundário, e, portanto, menos importante, na condição de Márcia? Sem insistir nessas questões não respondidas, a neurologista fez outra tentativa: trocou de remédio. Agora era a Ritalina o melhor remédio para o caso, apesar da pouca idade da paciente. Justificativa: a hiperatividade é grave - mesmo se não há no prontuário qualquer descrição sobre sua natureza. Aos quatro anos, Márcia fez um eletroencefalograma e, por este exame sugerir "anormalidades indicativas de epilepsia focal", foram receitadas a Carbamazepina e o Tegretol, além da Ritalina. Mais tarde considerados desnecessários, esses remédios foram substituídos por Depakene. Receitou-se ainda Anafranil, um antidepressivo que, à semelhança dos medicamentos anteriores, não é comumente indicado para crianças menores de seis anos. Esse remédio também foi suspenso, sem qualquer indicação no prontuário nem para seu uso, nem para a suspensão.

Finalmente, solicita-se uma Tomografia Computadorizada de Crânio (sic) e recomenda-se: "após controle das crises - tratar comportamento" com "psicologia e psicomotricista/psicopedagogia para auxiliar em sua atividade escolar".

É interessante notar que o encaminhamento realizado pela neuropediatria para a saúde mental se dá pelos mesmos motivos que nortearam o encaminhamento para a neurologia, dois anos e meio antes: distúrbios de comportamento secundários. Durante dois anos e meio, a neurologia fizera a) inúmeras experiências medicamentosas por causa do comportamento, e tentou contornar efeitos secundários à medicação; b) um eletroencefalograma que levantou a suspeita de uma epilepsia focal e, c) como não cessaram as queixas, a indicação de uma tomografia do cérebro, provavelmente na tentativa de ver na imagem o mal que estaria acometendo Márcia. Ao fim disso tudo, jogava-se a toalha para o que tange o comportamento e encaminhava-se a menina para uma profilaxia psicopedagógica.

Atendida no setor da saúde mental, Márcia inicia entrevistas preliminares para um atendimento psicanalítico. Ali, o diagnóstico é de histeria; os tremores dos membros são provavelmente sintomas conversivos determinados pela história dela e inscritos no corpo a partir dos efeitos medicamentosos a que fora submetida 


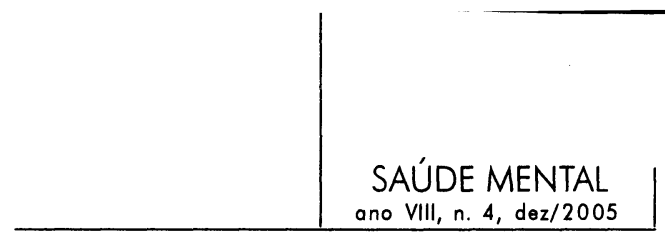

em tão tenra idade, fazendo valer a hipótese da complacência somática à qual Freud (1905, p. 45) alude na determinação do sintoma histérico. Não foi possível observar hiperatividade, durante todo período de atendimento na saúde mental.

O destino do caso Márcia no hospital é muito significativo, pois demonstra claramente a falta de comunicação e de conhecimento existente entre as equipes. Durante mais de seis meses foram feitas reiteradas tentativas de contato com a neurologia, mas não foi possível uma única entrevista com algum médico que atendera Márcia. Nas entrevistas preliminares, a menina de cinco anos contou muitas histórias, e sua mãe, que finalmente encontrou alguém com quem falar, pôde tecer observações sobre as difíceis condições de vida em que ambas se encontravam, e que certamente dizem muito mais respeito a um problema a ser levado ao serviço social do que à neurologia. Nunca antes se procurara escutar esta senhora, ao contrário, solicitou-se uma tomografia do cérebro. "A neuropediatra pediu essa tomografia, mas eu não tenho como fazê-la e fiquei com medo de dizer isso para ela, pois ela é muito rígida". Refém de uma mãe alcoolista e violenta - o que certamente teve um papel na transferência com a neuropediatra -, na casa de quem essa senhora cria seus filhos, a mãe de Márcia diz não ter a coragem necessária para mudar de vida e ir embora, apesar de sua própria mãe aterrorizar os netos com crises agressivas que deixam Márcia apavorada. Estas cenas violentas ocorrem muito frequientemente à noite, razão de Márcia apresentar distúrbios do sono.

Por que é tão difícil parar um pouco e se dedicar a tentar escutar a história de um paciente? O caso Márcia é paradigmático para isso. Aconteceu recentemente, e num contexto hospitalar que recebe alunos, ou seja, um hospital que, além da assistência, também visa a formação de novos profissionais. Como já dito, o caso Márcia denuncia a ausência de intercâmbio entre os diferentes serviços num grande hospital; a dificuldade de dedicação a um caso clínico decorrente, provavelmente, da grande quantidade de pacientes a serem atendidos; a tentativa de solucioná-los, através da medicação, na esperança de, com isso, responder rapidamente a uma queixa; o uso do rápido diagnóstico, a partir nem mesmo de uma fenomenologia e sim de índices de comportamento; e quando isso se mostra um pouco falacioso, lança-se mão de aparelhos - dos mais tradicionais (eletroencefalograma) aos mais modernos (tomografia) - para então se fiar em resultados inferidos, nem sempre verdadeiros. $\mathrm{O}$ acompanhamento psicológico é medida profilática para possíveis problemas de aprendizagem, e assim por diante... Velhas questões que se repetem.

No entanto, há novas: por que o encaminhamento para a neurologia se o exame clínico levanta a hipótese de distúrbio de comportamento? Por que a neurologia procura diagnosticar, tratar tais distúrbios, e acredita saber responder a tal encaminhamento? Por que se utiliza, para responder, de uma medicação que 


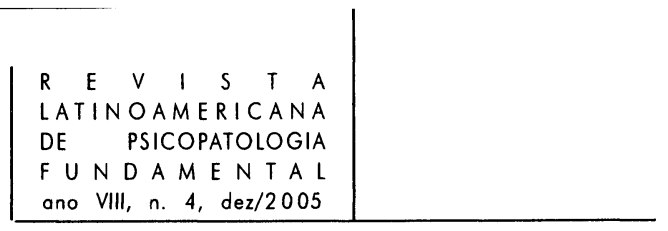

é, na origem, psiquiátrica? Tratar-se ia aqui de uma crença ou de uma tentativa de subsumir a clínica psiquiátrica, psicológica ou mesmo psicanalítica? Evidentemente são perguntas que poderiam ter sido respondidas se tivesse sido possível falar com os médicos que atenderam Márcia; na ausência de respostas, ficam as perguntas. A idéia subjacente, no entanto, é clara: acredita-se que um problema de comportamento possa ter uma causa única e, sobretudo, cerebral, razão de se receitar uma medicação que intervenha quimicamente. Além disso, acredita-se que com uma técnica de exame mais avançada, é possível ver esta causa em retratos do corpo interno, em imagens. Em nenhum momento é sequer levantada a hipótese de que talvez haja alguma coisa em Outra cena... O fato é que o sujeito Márcia e o sujeito que é mãe de Márcia só puderam ser efetivamente levados em conta, enquanto sujeitos, quando chegaram finalmente à saúde mental porque ali havia alguém que se interessou em fazer entrevistas preliminares para um atendimento psicanalítico.

\section{Da clínica da res cogitans à saúde mental}

Não há sujeito sem corpo, isso é necessário. Eis onde se justifica o paradoxo observado acima, do texto de Berlinck. Mas no próprio âmbito dessa necessidade, há muito real em jogo. Tal é a dificuldade que se presentifica quando se quer trabalhar na clínica a partir de um discurso que se dirige ao sujeito. Mais do que isso: quando se procura transmitir a psicanálise, no contexto dos serviços de saúde mental, para os colegas de trabalho que crêem, muitas vezes, encontrar maior conforto no cientificismo, no diagnóstico rápido e no poder dos medicamentos. Dessa maneira, tenta-se driblar o mal-estar na cultura, para não experimentar o real da clínica. Ao foracluir ${ }^{9}$ o sujeito, a medicina tenta protegerse ante o surgimento do inexplicável, por exemplo, da própria resistência à cura de determinado paciente seu. Mas é também por estar avisado do inassimilável, ou seja, de que não pode tudo curar, que o médico às vezes se defende da emergência de todo sinalizador do mal-estar, inclusive o seu próprio. Impossível sequer supor nesse contexto qualquer avanço do conhecimento sobre o sofrimento psíquico, já que para isso é fundamental levar em conta o mal-estar na cultura, conceituado por Freud para todos os campos, em 1930.

Para fazer frente a isso é preciso a ancoragem teórica que a psicanálise pode dar, por ter descentrado o sujeito da consciência. O inconsciente postulado por

9. Um tipo de negação que leva à escotomização e à expulsão, retomado também por Lacan no contexto da psicose (cf. Kaufmann, 1993, p. 214-5). 


\section{SAÚDE MENTAL}

ano VIII, n. 4, dez/2005

Freud fez um corte na história da subjetividade que, até então, contava com a primazia da consciência. Sem essa especificação, não é possível sustentar o sujeito na articulação com o discurso da ciência. Com efeito, todas as tentativas de pensar o homem a partir da consciência levam à foraclusão do sujeito. Donde: a clínica psicanalítica exige a ancoragem teórica que implica grande dedicação e investimento para cada psicanalista que quiser arriscar uma conexão com outros campos. E mais: é preciso saber que nem todos os clínicos têm a possibilidade de fazê-lo, mas que é função do psicanalista transmiti-lo em cada interlocução. Como então?

Sujeito de e sujeito à fala, nosso paciente existe simbolicamente como marca mnêmica, significante, ou ainda, traço; ex-siste como efeito ao que escapa do simbólico - no umbigo do sonho, no Unheimliche, no mais além do princípio do prazer - e, mesmo assim, tem uma consistência, uma gestalt na qual procura se ver representado. É porque todas essas coisas só se articulam de forma claudicante que o sujeito sofre e sintomatiza na tentativa de articulá-las de algum jeito. Cansado dessas tentativas, meio sem jeito, busca tratamento. Toda sua demanda se tece, a partir da fala, nas cadeias associativas que surgem na transferência, permitindo entrever que o próprio sujeito é efeito de tal tecedura. Mas isso não é uma rede? Sem dúvida.

Conceito muito atual, se adapta em particular para pensar as redes tanto do pensamento - res cogitans - quanto das estruturas neurais, além, é claro, de já ter sido usado na conceituação da articulação da rede dos significantes que determinam o sujeito. E se pudéssemos supor não uma simples clínica da res cogitans - como poderiam ser entendidas as contribuições atuais das ciências cognitivas, da psicologia cognitiva e do estudo correspondente do pensamento e da linguagem, que ainda se calcam completamente na consciência, mas uma clínica que, ao primaziar o sujeito do inconsciente, pode se associar aos esforços das ciências conjecturais na articulação do saber?

Assim como os dois movimentos - o do cientificismo e o das ciências conjecturais - que se instituiram com a primazia do discurso da ciência em todos os campos dos saberes e das práticas, as próprias neurociências se dividem entre mais organicistas e mais lógicas. Há aquelas que apostam na hipótese localizacionista; outras que sustentam a hipótese funcionalista e ainda outras, em particular aquelas que trabalham com as redes neurais, que visam hipóteses matemáticas (cf., por exemplo, Sutton e Ratey, 1998, p. 180). Tal pluralidade das neurociências "pretende abranger desde a microestrutura do cérebro e o funcionamento subneuronal,,$^{10}$ às redes de relações entre neurônios, chegando até

10. O nível sub-neuronal é do funcionamento interno ao próprio neurônio, distinto do nível neuronal que é anatômico. 


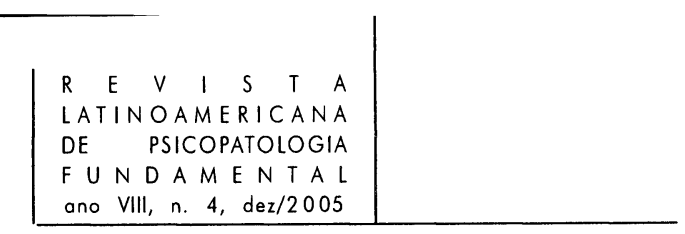

às relações que se dão no organismo como um todo" (Campos, 2001, p. 9). No discurso comum, e particularmente aquele praticado hoje nas clínicas neurológica e psiquiátrica, ${ }^{11}$ se desenvolve a crença numa neurociência una, que cai na mesma falácia já denunciada por Freud há mais de cem anos no contexto do estudo das afasias. Na realidade, as verdadeiras pesquisas - e já pudemos observá-lo acima no próprio âmbito das pesquisas de laboratório - se dão de forma bem diferente! O cientista sabe que o mais importante a ser feito é bem delimitar seu campo. E se não for mero instrumento do discurso capitalista, está advertido das implicações ideológicas que buscam submeter a ciência...

Há, pois, todo um outro campo possível, quando neurocientistas procuram uma interlocução com as psicologias. Em algum lugar, até sabem que a psicanálise tem uma teoria que muito poderia contribuir para suas pesquisas, mas quem são seus interlocutores do lado dos psicanalistas? Será que os psicanalistas têm um conhecimento suficiente da descoberta freudiana para poder transmiti-la na psicanálise em extensão? Não poucas vezes escutamos que é desnecessária a teoria, ou até mesmo lemos confissões de sua ignorância (Soussumi, 2001), o que nos deixa bastante preocupados quanto a uma transmissão viável. O mesmo se dá no contexto dos serviços de saúde mental. Até onde não somos nós mesmos os responsáveis pela ainda maior resistência à psicanálise para além daquela que lhe é intrínseca (Freud, 1914)? Resistências outras que provêm de nossa própria dificuldade em transmitir a descoberta freudiana para nossos colegas de trabalho e de pesquisa...

Senão, vejamos. Neurocientista de reconhecimento internacional, Edelman foi capaz de escrever que "há um longo caminho entre a acetilcolina e o tabu do incesto, e precisamos ter muito cuidado quando relacionamos estados fisiológicos aos conteúdos da consciência em animais falantes (in language-bearing animals)" (Edelman, 1989, p. 212, tradução nossa). Enquanto cientista, ele sustenta um campo diferente do das descobertas de uma ciência da consciência e não pretende ter a capacidade para criticar Freud. Mesmo assim, quando procura saber alguma coisa mais sobre a psicanálise, seus interlocutores nesse campo visivelmente deixam a desejar... pois, como outros, privilegia o inconsciente dinâmico em detrimento ao econômico (Freud, 1915), além de definir o inconsciente muito mais pelo que não é do que pelo que é: não é atividade consciente... o que deixa de fora toda articulação lógica do processo primário, uma rede, aliás, muito particular!

Para concluị sugerimos: o aprofundamento do estudo teórico da psicanálise por uma prática que sustente sua transmissão na multidisciplinaridade tanto da clínica quanto da pesquisa científica. Sem tal dedicação e investimento não há

11. Cf. caso Márcia e a observação comentada de Gilda Paoliello, respectivamente. 
como fundamentar a transmissão da psicanálise que, sabemos, sempre será a oferta de uma outra coisa, da Outra cena, para aqueles que puderem articular uma demanda. Nem todos podem, uns não querem... não é com estes que podemos contar!

Levantamos a hipótese de que é somente com um profundo conhecimento da psicanálise, mais ainda, somente a partir de se estar definitivamente atravessado pela psicanálise, que nós psicanalistas poderíamos nos render ao reconhecimento de nossa total ignorância quanto às neurociências. Que nós psicanalistas poderíamos nos dirigir a este saber que, distintamente da psicanálise, é da ordem da ciência, para querer saber alguma coisa sobre ele. Não para nos dar melhores instrumentos, nem para nos ensinar o que é, finalmente, a mente humana - pois se somos profundos conhecedores da psicanálise devemos ter ao menos uma resposta para tal questão -, mas para saber e poder debater com elas em prol de um avanço.

\section{Referências}

Abbgnano, N. (1971). Dicionário de filosofia. São Paulo: Martins Fontes, 2000.

BERLiNCK, M. T. (1998). O que é psicopatologia fundamental. In: Psicopatologia fundamental. São Paulo: Escuta, 2000.

(1999). Catástrofe e representação. Notas para uma teoria geral da psicopatologia fundamental. In: Psicopatologia fundamental. São Paulo: Escuta, 2000. p. 27-56.

BILDER, R. Preface. In: Neuroscience of the mind on the centennial of Freud's Project for a scientific psychology. Annals of the New York Academy of Sciences, v. 843, maio de 1998.

Campos, F. S. Psicanálise e neurociência: dos monólogos cruzados ao diálogo possível. 2001. Tese (doutorado em Psicologia). Depto. de Psicologia, Pontifícia Universidade Católica do Rio de Janeiro.

Clavreul, J. (1978). A ordem médica - poder e impotência do discurso médico. São Paulo: Brasiliense, 1983.

Edelman, G. M. The Remembered Present: A Biological Theory of Consciousness. New York: Basic Books, 1989.

FÉdidA, P. Prefácio. In: Pereira, M.E.C. Pânico e desamparo. São Paulo: Escuta, 1999.

FigueIREDo, A. C. Vastas confusões e atendimentos imperfeitos. Rio de Janeiro: RelumeDumará, 1997.

Foucault, M. (1980). O nascimento da clínica. Rio de Janeiro: Forense Universitária, 1998. 


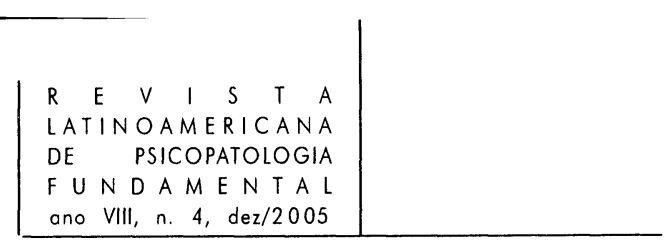

Freud, S. (1890). Tratamento psíquico (ou anímico). In: Edição Standard Brasileira das Obras Psicológicas Completas de Sigmund Freud. Rio de Janeiro: Imago, 1989. v. 7.

(1891). A interpretação das afasias: um estudo crítico. Lisboa: Edições 70, 1977.

(1895). Projeto para uma psicologia científica. In: Edição Standard Brasileira das Obras Psicológicas Completas de Sigmund Freud. Rio de Janeiro: Imago, 1987. v. 1 .

(1900). A interpretação dos sonhos. In: Edição Standard Brasileira das Obras Psicológicas Completas de Sigmund Freud. Rio de Janeiro: Imago, 1987. v. 4.

(1905). Fragmentos da análise de um caso de histeria. In: Edição Standard Brasileira das Obras Psicológicas Completas de Sigmund Freud. Rio de Janeiro: Imago, 1989. v. 7.

(1914). História do movimento psicanalítico. In: Edição Standard Brasileira das Obras Psicológicas Completas de Sigmund Freud. Rio de Janeiro: Imago, 1974. v. 12.

(1915). O inconsciente. In: Edição Standard Brasileira das Obras Psicológicas Completas de Sigmund Freud. Rio de Janeiro: Imago, 1974. v. 12.

(1927). A questão da análise leiga - pós-escrito. In: Edição Standard Brasileira das Obras Psicológicas Completas de Sigmund Freud. Rio de Janeiro: Imago, 1976. v. 20.

(1930). Mal-estar na cultura. In: Edição Standard Brasileira das Obras Psicológicas Completas de Sigmund Freud. Rio de Janeiro: Imago, 1974. v. 21.

(1938). Esboço de psicanálise. In: Edição Standard Brasileira das Obras Psicológicas Completas de Sigmund Freud. Rio de Janeiro: Imago, 1974. v. 23.

Garcia-Roza, L. A. Freud e o inconsciente. Rio de Janeiro: Jorge Zahar, 1988.

Gordon, N. (1986). O físico. Rio de Janeiro: Rocco, 1988.

Henneman, R. H. (1966). O que é psicologia. Rio de Janeiro: José Olympio, 1985.

JACKsON, H. On affections of speech from disease of the brain. In: Selected writings of John Hughlings Jackson. Londres: Hodder and Stoughton Limited, 1878. v. 2.

Kaufmann, P. (1993). Dicionário enciclopédico de psicanálise: o legado de Freud e Lacan. Rio de Janeiro: Jorge Zahar, 1996.

KunN, Thomas S. The structure of scientific revolutions. Chicago: Chicago University Press, 1970.

LACAN, J. (1953). Função e campo da fala e da linguagem. In: Escritos. Rio de Janeiro: Jorge Zahar, 1998.

(1966). Psicoanalisis y medicina. In: Intervenciones y textos. Buenos Aires: Manantial, 1985. v.1. 
(1968-9). O Seminário. Livro 17. O avesso da psicanálise. Rio de Janeiro: Jorge Zahar, 1992.

Lalande, A. (1926). Vocabulário técnico e crítico da filosofia. Rio de Janeiro: Martins Fontes, 1999.

Laurent, E. (2000). Há algo de novo nas psicoses? Revista Curinga. Belo Horizonte, n. 14, 2000.

Solms, M. Before and after Freud's "Project". Annals of the New York Academy of Sciences, v. 843, maio de 1998.

Soussumi, Y. Afetos, emoções, instintos, psicanálise e neurociência. Alter - Jornal de estudos psicanalíticos, Brasília, v. 20, n. 1, p. 75-106, 2001.

SutTon e Ratey. Beyond the "Project": it's about time. Annals of the New York Academy of Sciences, v. 843, maio de 1998.

Versão inicial recebida em abril de 2005

Aprovado para publicação em setembro de 2005 